\title{
Developmental Trends in Eating Self-Regulation and Dietary Intake in Adolescents
}

\author{
Diana Tăut* and Adriana Băban \\ Babeş-Bolyai University, Romania \\ Helge Giese \\ University of Konstanz, Germany \\ Margarida Gaspar de Matos \\ University of Lisbon, Portugal \\ Harald Schupp and Britta Renner \\ University of Konstanz, Germany
}

\begin{abstract}
Background: Research suggests that while capacities for self-regulation gradually improve during adolescence, eating habits become unhealthier. This study investigated whether there are age-related patterns in using self-regulation strategies (SRS) as well as in the self-reported dietary intake of fruit, vegetables, and unhealthy snacks. Moreover, we tested the strength of the relationship between different SRS (aimed at goal versus aimed at temptations) and dietary intake across different ages in adolescents. Methods: In total, 11,392 adolescents (49.5\% boys, age range 10-17) from nine European countries took part at this study. Eating SRS, daily intake of fruit, vegetables, and unhealthy snacks were assessed. Results: Older adolescents had lower scores on self-regulation measures compared to younger ones, as well as lower intakes of fruit and vegetables and higher intakes of unhealthy snacks. The strength of the associations between strategies aimed at goal and unhealthy dietary intake, as well as between strategies aimed at temptation and healthy dietary intake, were generally small and/or insignificant. There were small age differences in the direction and strength of these patterns. Conclusion: The trends in SRS and dietary intake of fruit, vegetables and unhealthy snacks suggest that middle (13-15-years-old) but also older adolescents might benefit greatly from interventions focused on boosting eating SRS.
\end{abstract}

Keywords: adolescents, development, dietary intake, self-regulation strategies

* Address for correspondence: Diana Tăut, Department of Psychology, Babeş-Bolyai University, Republicii Street 37, 400015 Cluj-Napoca, Romania. Email: dianataut@psychology.ro 


\section{INTRODUCTION}

Adolescence is a period of marked transformations in a youngster's life (pubertal changes, increased influence of peer group, cognitive and emotional changes) that may prove critical in setting lifestyle trajectories with implications for adult health. Among these, unhealthy eating plays a major role, as it is predictive for long-term eating habits and further unhealthy weight gain (Whitaker, Wright, Pepe, Seidel, \& Dietz, 1997), as well as for a heightened risk for diabetes melitus, cardiovascular disease, or certain types of cancer (Tirosh et al., 2011).

One of the best predictors of accomplishing healthy eating goals in adolescents is the use of self-regulation strategies (SRS) (Kalavana, Maes, \& De Gucht, 2010). When compromised, these strategies increase the pace and the amount of weight gain from childhood to adolescence (Francis \& Susman, 2009). From a self-regulation perspective, unhealthy eating can be framed in terms of a conflict between immediate urges on one hand, and long-term reasoned plans and standards on the other (e.g. Baumeister \& Heatherton, 1996; Carver, 2005; Vohs \& Baumeister, 2004). Enhanced by key changes in brain development (maturation of prefrontal cortex) and in the microenvironment (growing influence of peer group, transition through different school structures) as well as by social pressure for selecting and reaching personal goals, self-regulation gradually improves between lower-end adolescence (11-12 years old) and the upper end (17-18 years old) (Gestsdottir \& Lerner, 2008; Steinberg et al., 2008).

Although SRS refine during adolescence, dietary habits become unhealthier. The prevalence of daily fruit consumption decreases in both genders, from 42 per cent in 11-year-olds, down to 31 per cent in 15-year-old European adolescents. The reverse effect is evident for daily soft-drink consumption, with a steady increase in the same age interval and significant age differences in most of the 39 European countries involved in the Health Behavior in School-Aged Children (HBSC) study (Currie et al., 2012). These are disconcerting results, as research shows that better self-regulation translates into healthier eating patterns in adolescents (Junger \& Van Kampen, 2010; Kalavana et al., 2010). Also, it is associated with decreases in body mass index (BMI) in the transition from childhood to adolescence (Duckworth, Tsukayama, \& Geier, 2010) and to less sensitivity to food rewards (Bourget \& White, 1984; Geller, Keane, \& Scheirer, 1981; Nederkoorn, Braet, Van Eijs, Tanghe, \& Jansen, 2006).

One explanation for these paradoxical patterns suggests that, while resources for self-regulation increase with age, that is not necessarily true for their intentional use. Older adolescents may be less inclined to actively control their eating compared to their younger counterparts, although they are well aware of the benefits of healthy eating (Crăciun, Tăut, \& Băban, 2012; Stok, 
De Vet, De Ridder, \& De Wit, 2012). Although there are few data on the extent of the use of intentional eating self-regulation in adolescence and its effects on dietary intake, even less is known about whether eating selfregulation is stable or, rather, changes over time. If eating tends to become less healthy, then we might assume that intentional use of eating selfregulation also decreases with age. Research converges on this hypothesis in different self-regulation domains, showing steady declines in intentional selfcontrol from childhood to adolescence in selection, optimisation, and compensation (SOC) self-regulatory strategies (Bowers et al., 2011); declines in the self-regulated learning and grades (Simmons \& Blyth, 1987) or in selfefficacy beliefs (Urdan \& Midgley, 2003). Building on these findings, the present study investigates whether more pronounced unhealthy eating in older adolescents is also increased by decreased rates of intentional eating self-regulation.

Also, the strength and the association of SRS and dietary intake may vary across younger compared to older adolescents. Self-regulatory success equally depends on the effectiveness of both temptation-focused strategies, aimed at decreasing the appeal of immediate urges, and goal-focused strategies used for boosting goal attainment, both of which can be broken down into behavioral actions and changing the psychological meaning (Fishbach \& Converse, 2011; Fishbach, \& Trope, 2005; Trope \& Fishbach, 2000). Research findings suggest that different SRS may have asymmetrical effects over eating, i.e. temptation-focused strategies are more efficient in overcoming immediate unhealthy temptations while goal-related strategies are more effective in the long-term aligning of behavior with self-set standards (healthy eating). Thus, goal-directed strategies such as planning are efficient in promoting healthy eating, like fruit and vegetable consumption (Adriaanse, De Ridder, \& De Wit, 2009) but may not be as efficient in reducing unhealthy eating (e.g. Adriaanse, Vinkers, De Ridder, Hox, \& De Wit, 2011). Moreover, they may even have ironic effects by strengthening the undesirable habit (e.g. Adriaanse, van Oosten, De Ridder, De Wit, \& Evers, 2011). On the contrary, temptation-focused strategies - thinking about something else (changing the psychological meaning) or thinking about the food temptation more abstractly-have proved beneficial in delaying gratification in children (Mischel, 1996; Metcalfe \& Mischel, 1999) and have been associated with lower intake of unhealthy snacks and soft drinks in adolescents (Luszczynska et al., 2013). Given that with age, adolescents gain more control over their food choices and are more exposed to obesogenic stimuli (Hill, 2002), the self-regulation challenges they have to tackle are different from those encountered by their younger counterparts. Hence, older adolescents have more occasions to use SRS aimed at managing unhealthy temptations and at ensuring goal striving as well. However, they may also be more prone to act on impulse (Steinberg et al., 2008) and thus probably try to inhibit these 
unwanted impulses if they interfere with the healthy eating goal. Here, this would translate into a stronger relationship between strategies aimed at temptations and healthy snacking habits. Hence, a meaningful step forward would be to investigate the strength of the association between self-regulation and dietary habits at different stages of development (ages).

Starting from these theoretical premises, the aims of the present study were twofold: (a) to assess the age-related dynamics in the use of eating selfregulation and in the intake of fruit, vegetables, and unhealthy snacks; and (b) to assess the extent to which the strength and the direction of the relationships between eating SRS and dietary intake of fruits, vegetables, and unhealthy snacks vary across ages.

\section{METHODS}

\section{Study Participants and Procedure}

A sample comprising 11,392 adolescents (49.5\% males) from nine European countries was recruited for the study, as part of a larger cross-country collaborative project involving Belgium ( $n=1,134 ; 54.7 \%$ males), Denmark ( $n=1,165 ; 50.1 \%$ males), Finland ( $n=1,157 ; 48 \%$ males), Germany ( $n=1,397 ; 48.7 \%$ males), the Netherlands ( $n=1,274 ; 53.6 \%$ males), Poland ( $n=1,445 ; 43.5 \%$ males), Portugal ( $n=1,189 ; 48.4 \%$ males), Romania ( $n=1,401 ; 48.8 \%$ males), and the United Kingdom ( $n=1,230 ; 51.2 \%$ males). Schools were selected based on their availability to participate. However, the selection of schools was made in order to cover different regions (rural and urban) as well as more affluent and poorer areas. Adolescents were aged 10 to $17(M=13.21, S D=2.00)$. More details regarding the sample and the study procedure can be found in De Vet et al. (2014).

The research was conducted in accordance with the ethical regulations in each country and with the approval of country-specific ethical boards. Informed consent regarding participation in the study was obtained from all participants prior to data collection. The questions were originally developed in English and country-language versions were obtained by translating the items by researchers fluent in English with input from native English speakers. Finally, the items were back-translated into English.

\section{Measures}

Self-Reported Snacking. Unhealthy snacking was taken as a proxy for unhealthy dietary intake and daily fruit and vegetable consumption as a measure of healthy dietary intake. Studies show that increased fruit consumption (Alinia, Hels, \& Tetens, 2009) as well as increased vegetable intake (te Velde, Twisk, \& Brug, 2007) are associated with lower body weight in ado- 
lescents and adults. Prototypical (un)healthy food intake was assessed with three single items tapping the average daily intake of fruit, vegetables (Johnson, Wardle, \& Griffith, 2002), and unhealthy snacks (Lally, Bartle, \& Wardle, 2011). In order to assess unhealthy snacking more reliably, adolescents were prompted to count as snacks country-specific unhealthy items such as chocolate, cookies, crisps, etc. Adolescents were required to indicate their consumption on a 0 (less than $1 /$ none) to 5 (more than 4) scale with the following items: (1) How many servings of fruit do you eat on an average day? (2) How many serving spoons of cooked or raw vegetables do you eat on an average day? (3) How many snacks do you eat on an average day? (You may count as one snack: one handful of crisps or pretzels, a handful of biscuits/winegums, one chocolate bar, etc.)

Eating SRS. The Tempest Self-Regulation Questionnaire for Eating (TESQ-E; De Vet et al., 2014) was used in order to assess eating selfregulation. The scale has 24 items, tapping on different eating SRS. TESQ-E describes three higher-order approaches subsuming lower-level ones. The first one is action towards temptation comprising avoidance (e.g. If I am in town, I make sure that I don't go by fast-food places) and control of temptation (e.g. If I am in front of the PC, I make sure there is some healthy food within reach). The second one is changing the meaning of temptation with distraction (e.g. If I have the urge to eat candy, I find something else to do) and suppression (e.g. If I want to eat unhealthy things, I just tell myself "no!"). The third one is actions towards goal which comprises items describing goal setting (e.g. I plan to bring a piece of fruit to school) and goal deliberation (e.g. If I feel like eating something unhealthy, I think about whether I really want it). The confirmatory factor analysis of TESQ-E $(N=11,392)$ showed that the theoretical distinction into three generic approaches addressing the goal or the temptation is statistically meaningful, NFI $=.93$, $\mathrm{CFI}=.93, \mathrm{RMSEA}=.043, \mathrm{AIC}=5530.33$.

Each of the three higher-order approaches was computed by averaging the scores on the two corresponding subscales and was subsequently used in all the analyses. The reliability was good for all three approaches: action towards goal (Cronbach's alpha $=.84$ ), action towards temptation (Cronbach's alpha $=.82$ ), and changing the meaning of temptation (Cronbach's alpha $=.85$ ). A detailed discussion regarding the psychometric properties of TESQ-E can be found in De Vet et al. (2014). Furthermore, the TESQ-E scale is publicly available in all nine languages at http://www.tempestproject .eu/tesq-e-questionnaires.

Body Mass Index (BMI). BMI was computed from self-reported weight (in kilograms) and height (in centimetres). In order to establish overweight/ obesity status, Cole, Bellizzi, Flegal, and Dietz (2000) cut-offs were 
employed. On average, adolescents reported a BMI $=20.01, S D=2.82$. In all, 24.1 per cent of the respondents were overweight and 2.1 per cent were obese. Although the data presented are not directly comparable since they vary in terms of sampling procedures, age ranges, and the year(s) of data collection, they are similar to those reported by the International Association for the Study of Obesity (IASO) (2010), showing that 20 per cent of school-aged children in the 27 European Union member states are overweight or obese. More pronounced differences were observed with data from HBSC (Currie et al., 2012), reporting that around 14 per cent of the 11-15-year-old adolescents from the nine countries involved in the present study were overweight or obese at the time of data collection (2008/09).

\section{Statistical Analyses}

Missing data varied from 0.2 per cent (gender) to 6.5 per cent (family affluence). We estimated the missing values with linear trend at point algorithm for SPSS. MANOVA with Bonferroni corrected post-hoc analyses was used to test for age differences in using eating SRS, as well as in intake of different foods. Effect sizes were reported by using the partial $\eta^{2}$ which reflects the variance explained by a given variable of the variance remaining after excluding variance explained by other predictors (Levine \& Hullett, 2002).

In order to test the strength of the relationship between the SRS and dietary habits across age groups, several steps were undertaken. A path model was specified in AMOS 20 (IBM Corporation, Chicago, IL) comprising direct relationships between the three eating self-regulation approaches with the three prototypical categories of food (daily fruit, vegetable, and snack intake). Before running the analyses, the intraclass correlations (ICC) at school level were calculated for all three independent variables as well as for the dependent ones, as an indicator of the possible non-independence due to clustering, by using the formula of ICC(1) provided by Bliese (2000). To test for the possible general causal model, we used the cross-validation in covariance structure modeling, by using the steps described in Byrne (2001). The hypothesised model specified the direct associations between selfregulatory approaches and intake of fruit, vegetables, and unhealthy snacks (see Figure 2). The sample was randomly split in half and the model was tested first in one subsample from the population included in the present study (calibration sample). The exogenous variables, as well as the endogenous ones, were asumed to be correlated and the error covariances were specified. This model was tested against an alternative, nonrecursive model (specifing relationships in both directions) first in the calibration sample (subsample 1) and further in a validation sample (subsample 2). Model-data fit was assessed based on fit indices such as the Tucker-Lewis Index (TLI), Comparative Fit Index (CFI), Normed Fit Index (NFI) and Root Mean 
Square Error of Approximation (RMSEA). In general, models with fit indices $>.90$ and a RMSEA $<.05$ indicate a good fit (Byrne, 2001). The comparative fit of these models was assessed by using chi-square difference tests. Finally, in order to test for possible age differences in the strength of associations between SRS and dietary intake of fruit, vegetables, and unhealthy snacks, a multiple group analysis was conducted with age categories in the 10-17-year-old interval as moderator. Critical ratios for differences of regression weights ( $z$-scores) were used to identify significant differences between groups on each path of interest, greater than 1.96 for 95 per cent CI, and greater than 2.58 for 99 per cent CI.

\section{RESULTS}

\section{Descriptive Statistics}

The intercorrelations between self-regulation approaches as well as their correlations with self-reported fruit, vegetable, and unhealthy snack intake are presented elsewhere (De Vet et al., 2014). Since BMI had non-significant or very weak associations with self-regulation and dietary intake (all $r \mathrm{~s}<.04$, all $p \mathrm{~s}>.01$ ), we decided to exclude it from the main analyses.

\section{Age Differences in Eating SRS and in Dietary Intake}

A MANOVA with age as between-subjects factor revealed significant effects of age on all three eating SRS: action towards goal, $F(7,11384)=96.75$, $p<.001$, partial $\eta^{2}=.06$; action towards temptation, $F(7,11384)=143.61$, $p<.001$, partial $\eta^{2}=.08$; changing the meaning of temptation, $F(7,11384)$ $=70.69, p<.001$, partial $\eta^{2}=.04$. Bonferroni adjusted post-hoc analyses revealed that adolescents aged 14 to 17 years old use eating SRS to a lesser extent than the 10-year-olds: action towards goal, all $M \mathrm{~s}_{14-17 \text { years old }}$ interval $=[2.19 ; 2.35], S D$ s interval $=[.84 ; .90]$ versus $M_{10 \text { years old }}=2.81$, $S D=.91$; action towards temptation, $M \mathrm{~s}_{14-17 \text { years old }}$ interval $=[2.03 ; 2.18]$, $S D \mathrm{~s}=[.74 ; .83]$ versus $M_{10 \text { years old }}=2.75, S D=.87$; changing the meaning of temptation, $M \mathrm{~s}_{14-17 \text { years old }}$ interval $=[2.07 ; 2.16], S D \mathrm{~s}$ interval $=[.79 ; .82]$ versus $M_{10 \text { years old }}=2.54, S D=.87$, all $p$ s $<.001$.

There was also a significant effect of age on the consumption of all foods, although effect sizes show small differences across groups: fruit intake, $F(7$, $11383)=47.161, p<.001$, partial $\eta^{2}=.03$; vegetable intake, $F(7,11384)=$ $13.307, p<.001$, partial $\eta^{2}=.008$; unhealthy snacks intake, $F(7,11384)=$ $11.915, p<.001$, partial $\eta^{2}=.007$. Post-hoc analyses with Bonferroni corrections revealed that adolescents aged 14 to 16 years reported eating healthy foods to a lesser extent compared to those aged 10-12: fruit intake, $M \mathrm{~s}_{14}$ 16 years old $=[1.54 ; 1.85], S D \mathrm{~s}=[1.29 ; 1.34]$ versus all $M \mathrm{~s}_{10-12 \text { years old }}=[2.07 ; 2.23]$, 

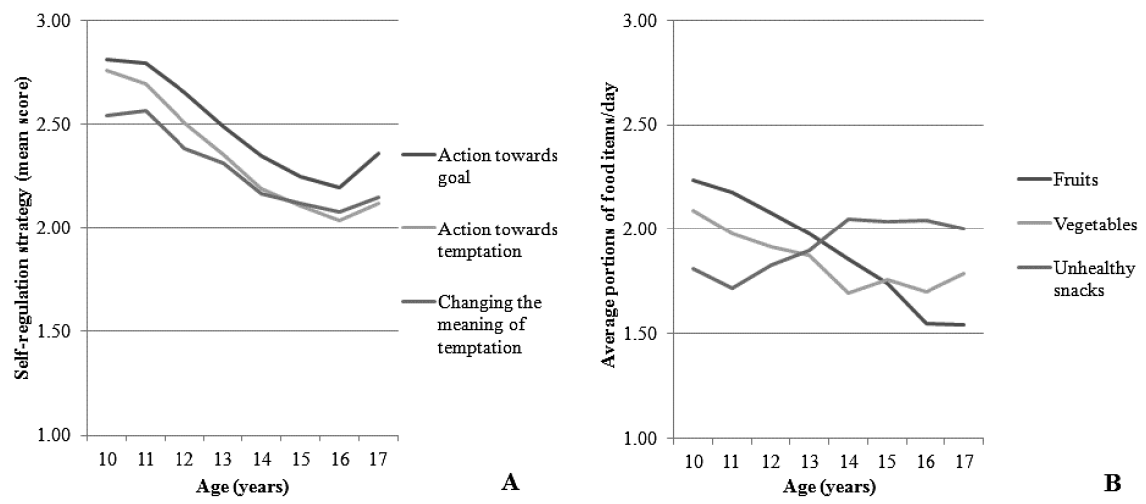

FIGURE 1. Age patterns in the use of eating SRS (Panel A, left) and in dietary intake (Panel B, right).

$S D$ s interval $=[1.25 ; 1.37]$, all $p s<.001$; vegetable intake, all $M \mathrm{~s}_{14-16}$ years old interval $=[1.69 ; 1.78], S D$ s interval $=[1.25 ; 1.32]$ versus all $M s_{10-12}$ years old interval $=[1.91 ; 2.08], S D$ s interval $=[1.38 ; 1.41], p s=.001$. Unhealthy snacking had the opposite pattern showing that adolescents aged 14 tol6 years ate more unhealthy snacks compared to those aged 10 to12: all $M s_{14-16 \text { years old }}$ interval $=[2.03 ; 2.04], S D$ s interval $=[1.44 ; 1.49]$ versus $M_{10-12 \text { years old }}$ interval $=[1.71 ; 1.82], S D$ s interval $=[1.32 ; 1.40], p s<.001$. There were significant differences between 17-year-olds and those aged 10 to 12 years old in the intake of fruit: $M_{17 \text { years old }}=1.54, S D=1.29, p s<.001$, and vegetables: $M_{17 \text { years old }}=1.78, S D=1.35, p s<.05$, but not for the intake of unhealthy snacks: $M_{17 \text { years old }}=2.00, S D=1.48, p \mathrm{~s}<.12$. Figure 1 shows the decreasing trend of all three strategies from 10-year-old to 17-year-old adolescents (Panel A) as well as the trends in dietary intake across the same age interval (Panel B).

\section{Group Differences in the Relationship between Self-Regulatory Strategies and Dietary Intake}

Test of the Default Model. The intraclass correlation coefficients (ICC) for all the variables were between -.011 and -.012, suggesting that 1 per cent of the variance for each variable can be attributed to school clustering (Bliese, 2000).

The model-data fit was similarly good in both samples: TLI $=1.00$, $\mathrm{CFI}=1.00$ and $\mathrm{NFI}=1.00$ (both samples), RMSEAs $=.000[90 \% \mathrm{CI}=.000-$ $.001]$. and .004 [ $90 \% \mathrm{CI}=.000-.036$ ), respectively, with no significant modellevel differences, $\Delta \chi^{2}(8)=6.26, p=.61$.

The alternative model (model 2) used for cross-validation had poorer model-data fit indices: TLI $=.87, \mathrm{CFI}=.97, \mathrm{NFI}=.97, \mathrm{RMSEA}=.092[90 \%$ 


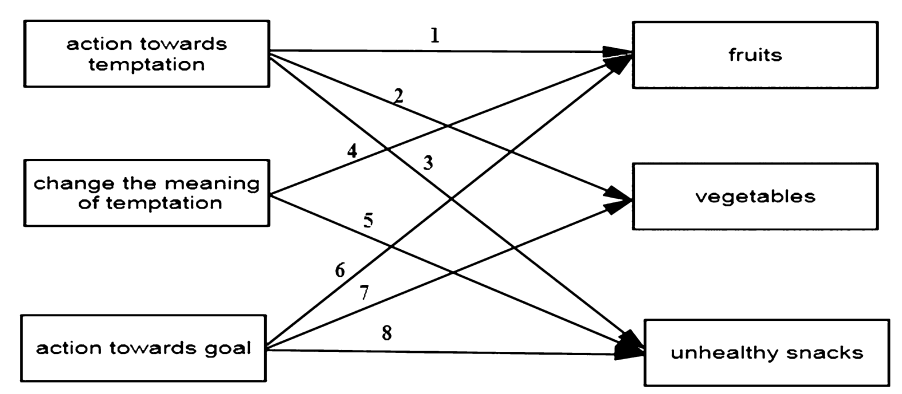

FIGURE 2. The hypothesised model of associations between eating selfregulatory strategies and dietary intake.

$\mathrm{CI}=.086-.098]$. Also, it was significantly different from the hypothesised model tested in the split-half samples: $\Delta \chi^{2}(5)=581.08, p=.001$ (alternative model versus calibration sample); $\Delta \chi^{2}(5)=580.12, p=.001$ (alternative model versus validation sample).

Regarding the hypothesised model, the relationship between action towards goal and healthy eating was stronger (fruit: $\beta=.35, p<.001$; vegetables: $\beta=.16, p<.001)$ than the relationship with unhealthy snacking $(\beta=.01$, $p=.23)$. Conversely, action towards temptations was weakly related to fruit intake $(\beta=.02, p=.07)$ and vegetable intake $(\beta=.06, p<.001)$ and more strongly related to unhealthy snacking $(\beta=-.24, p<.001)$. The same held true for the path from changing the meaning of temptation to eating fruit $(\beta=-.05, p<.001)$ that was weaker than the path towards unhealthy snacking $(\beta=-.14, p<.001)$.

\section{Age Differences in the Relationship between Self-Regulatory Strategies and Dietary Intake}

A constrained eight-group model (ages 10-17), assuming equal weights, intercepts, means, and covariances across age groups was tested, yielding good indices of model-data fit: $\chi^{2}(8)=11.88, p=.15$, TLI $=.99, \mathrm{CFI}=.99$ and $\mathrm{NFI}=.99, \mathrm{RMSEA}=.006[90 \% \mathrm{CI}=.003-.009]$. However, there was a significant difference in model fit when constraining all eight groups to be equal compared to the unconstrained model, $\Delta \chi^{2}(140)=346.09, p<.001$, suggesting that there may be model-level differences across groups. Therefore, we analyzed possible path differences for all eight age categories involved.

Table 1 displays the beta weights for each of the paths included in the model.

The strength and directions of the paths remained fairly similar across ages. However, there were some differences in the 16- and in the 17-year-old 


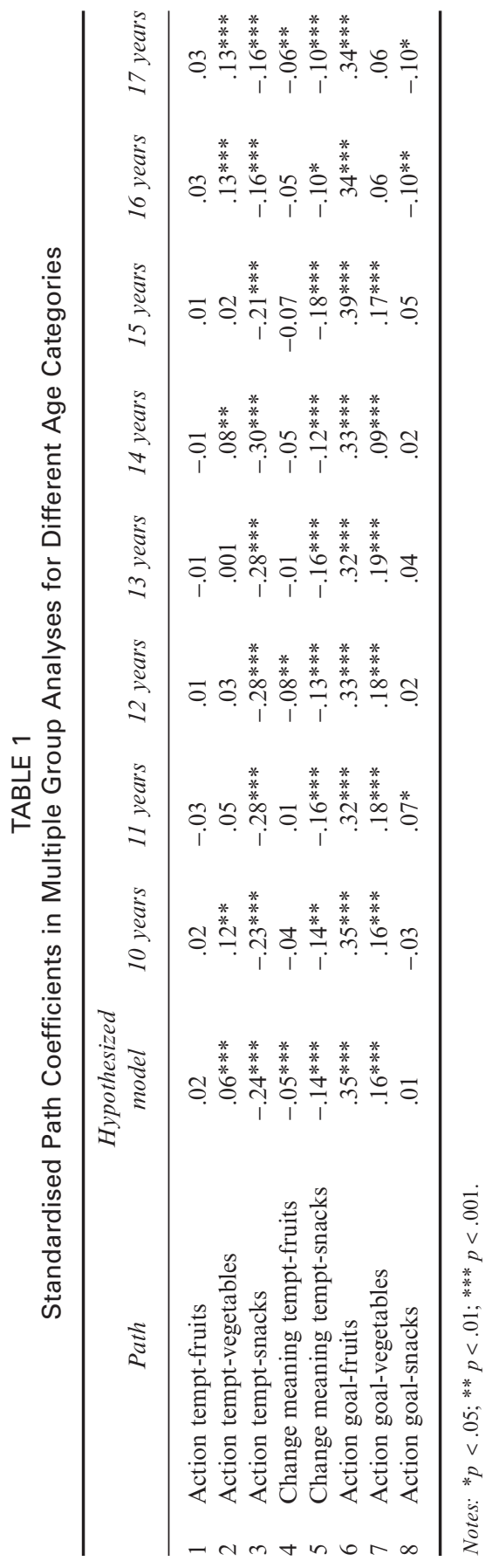


samples compared to the 12-, 13-, and 15-year-old ones, especially for the association between action towards temptation and self-reported consumption of vegetables, associations which were stronger in the older groups (16-year-olds) compared to the younger ones (12-year-olds). Also, the path from action towards goal and self-reported unhealthy snacking strengthened in the 16- and 17-year-old groups compared to ages 11,12,13, and 15. Conversely, the strength of the association between action towards goal and vegetable intake (Path 7) was weaker or non-significant in the 14- and 16-year-olds compared to the 11-, 12-, and 13-year-old groups. Nonetheless, the path from action towards temptation and unhealthy snacks became weaker in the 16- and 17-year-olds compared to the 12-, 13- and 15-year-olds (see Table 2).

\section{DISCUSSION}

The present results show that there is a steady decline in adolescents' eating self-regulation with increasing age and across all self-regulatory strategies: action towards goal, action towards temptation, and changing the meaning of temptation. This decline is more pronounced from early (10-12-year-olds) to mid-adolescence (14-16-year-olds), with a slow recovery in later adolescence (17-year-olds). The empirical literature describes a similar trend regarding the age dynamics of self-regulation in adolescence, with middle adolescents being more prone to engage in risk-taking and reckless behaviors than their younger or older counterparts (Steinberg et al., 2008). Involvement in unhealthy behaviors cannot be accounted for by lack of knowledge, ignorance, or irrationality (Reyna \& Farley, 2006). This view would imply that younger adolescents would display even less eating self-regulation and unhealthier dietary habits, given the immaturity of self-control processes at this developmental stage. However, both younger and older adolescents have higher eating self-regulation scores compared to this age group, trends which are reflected in the self-reported dietary intake of different foods. Specifically, there is a steady change in fruit and vegetable consumption from 10 years old to 15 years old, with a slow recovery at 16-17 years old. The reverse pattern is evident for unhealthy snack intake which has the highest scores in middle adolescence (14 years old) and remains stable until 17 years old. These patterns are highly similar to those reported in the HBSC cohort study, showing that there is a 16 per cent drop in percentage of individuals who report having daily breakfast, an 11 per cent drop in those eating fruits daily and a 7 per cent increase in the prevalence of soft drink consumption from age 11 to 15 (Currie et al., 2012). The results can be tracked down in the empirical literature (e.g. Steinberg, 2008), which suggests that middle adolescence is a period marked by heightened vulnerability to risk-taking and reckless behavior. This is probably due to a maturational gap between the 


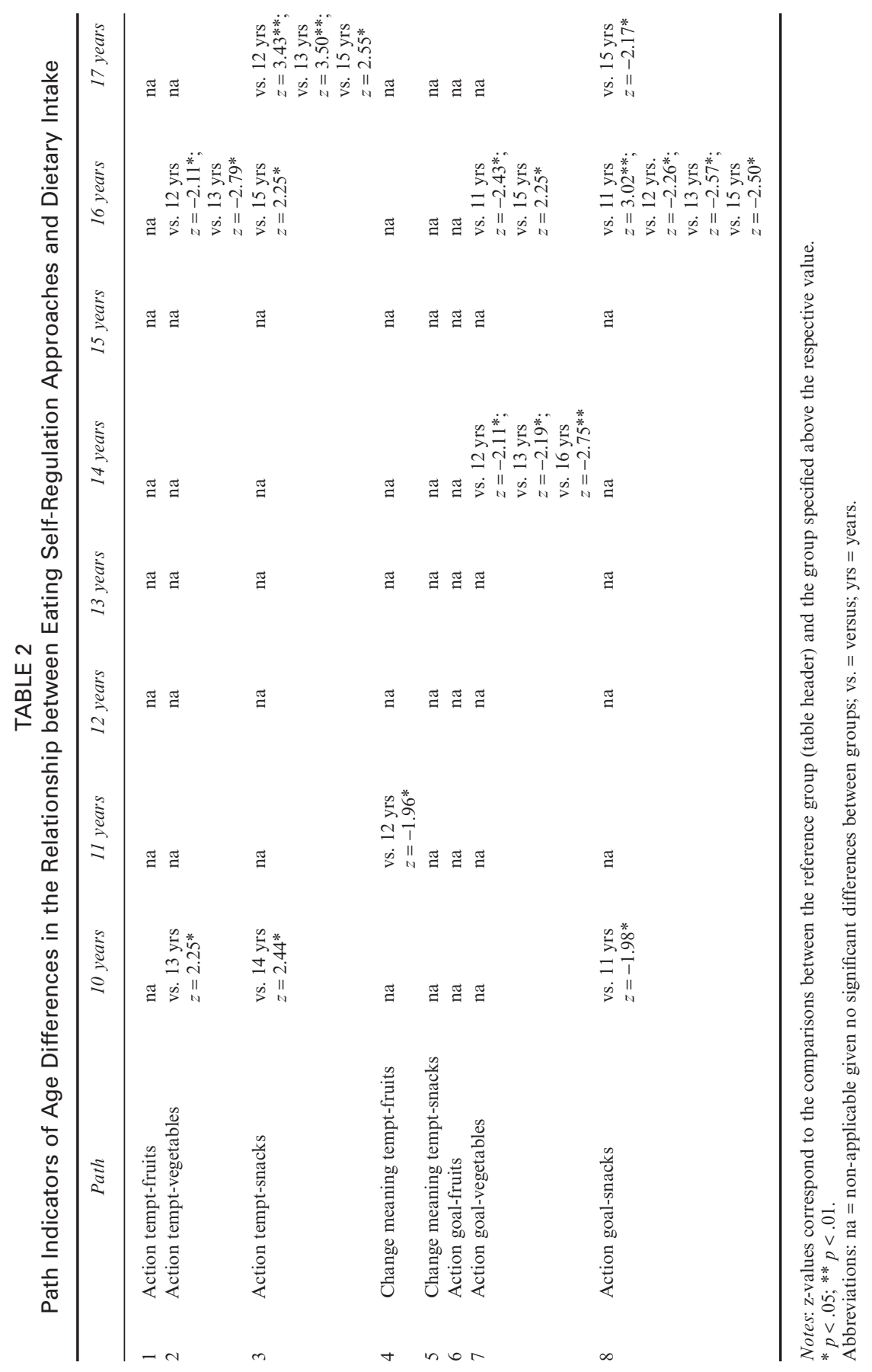


cortical areas responsible for self-regulation (e.g. the prefrontal cortex) and those involved in emotional processing. From this point of view, we might speculate that middle adolescents "omit" to implement SRS in contexts where this would be required, although that doesn't mean that they do not possess the abilities to regulate their behavior in accordance with external/ internal demands (Stok et al., 2012). Differences in the use of eating selfregulation doubled by differences in healthy dietary intake in middle compared to early adolescence suggest that interventions aimed at developing SRS should be targeted especially to the 13-15-year-old group. Boosting self-regulation skills and prompting adolescents to use self-regulation in food-related contexts might prove helpful.

The present findings have some additional implications. First, we showed that SRS targeted at decreasing the impact of temptations are more important in avoiding unhealthy eating and are less responsible for healthy eating. Conversely, SRS involved in goal setting and goal engagement are more involved in following a healthy eating goal (e.g. eating fruit) than counteracting the food temptation (avoiding unhealthy snacks). Therefore, different self-regulatory strategies might have different roles in securing both sides of the healthy eating goal. Similar ideas are described in other studies on selfregulation. Higgins' (1997) theory of "self-regulatory focus" suggests that people display tendencies to either avoid negative consequences associated with their acts (prevention focus) or to achieve higher-order goals (promotion focus), which trigger different self-regulatory strategies.

Next, we tested whether a model specifying the associations between selfregulatory strategies and self-reported dietary intake would be invariant across ages, or whether there are developmental differences in the strength and the directions of these associations. Our findings point to the conclusion that there is some age variance in the associations between self-regulatory strategies and eating, although the differences are rather small. Overall, goalrelated actions are better related to healthy self-reported dietary intake, whereas temptation-related ones are better connected with unhealthy snacking across age groups. Hence, even though older adolescents may be less inclined to control their dietary intake, the direction and the strength of different strategies and dietary habits does not change too much with age. Older adolescents benefit to the same extent as younger ones from goaldirected self-regulation when they try to increase fruit intake. However, the connection between goal-directed self-regulation and self-reported vegetable intake becomes insignificant in later adolescence (16-17-year-olds). Conversely, the same age groups (16-17-year-olds) might be more inclined to use strategies aimed at temptation when trying to both increase vegetable intake and decrease unhealthy snack consumption compared to their younger counterparts. This may indicate that in older adolescence, unhealthy temptations might activate healthy goal representations (awareness of the need to 
eat more vegetables when dealing with unhealthy snacks). Although these interpretations are speculative, they are nonetheless plausible, given that there is some research showing that unhealthy temptations might actually trigger the activation of a healthy goal (e.g. Fishbach, Friedman, \& Kruglanski, 2003; Kroese, Adriaanse, Evers, \& De Ridder, 2011).

The present study has some limitations. Given the cross-sectional design, causal relationships cannot be inferred from the data. Rather, these findings serve as a starting point for further studies that could longitudinally track adolescents to see whether SRS and eating habits vary across ages. The same holds true for the asymmetrical relationship between SRS and the intake of healthy versus unhealthy foods. Laboratory controlled studies as well as longitudinal ones may further explore whether indeed there is a difference in the effectiveness of using these SRS in managing unhealthy habits versus promoting healthier ones. Still, the present research provides a first insight into the matter and offers a solid starting point for future studies, as it shows that these asymmetrical relationships are rather similar across ages. Finally, self-reported daily consumption of fruit, vegetables, and unhealthy snacks is only a rough estimate of adolescents' dietary intakes. Further studies should include more valid measures of food intake such as nutritional diaries.

To conclude, this is one of the first studies to investigate age-related dynamics of eating SRS and dietary intake across different ages in adolescents. Our main finding was that the intentional use of eating self-regulation is employed to a lesser extent at older ages whereas self-reported unhealthy snack intake is reported more often. This makes it an excellent starting point for future research but also for intervention. Finally, we showed that, even though there are age differences in the intake of both healthy and unhealthy foods, the relationships between eating self-regulation and these habits is highly similar, which is again a strong basis for exciting new research in that area.

\section{CONFLICTS OF INTEREST}

The authors declare no conflicts of interest.

\section{ACKNOWLEDGEMENTS}

The research was supported by the European Community FP7 Research Program grant awarded to the TEMPEST consortium (Health-F2-2008223488). We thank all research partners and their collaborating organisations for their participation.

\section{REFERENCES}

Adriaanse, M.A., De Ridder, D.T.D., \& De Wit, J.B.F. (2009). Finding the critical cue: Implementation intentions to change one's diet work best when tailored to 
personally relevant reasons for unhealthy eating. Personality and Social Psychology Bulletin, 35, 60-71. doi: 10.1177/0146167208325612

Adriaanse, M.A., Van Oosten, J.M.F., De Ridder, D.T.D., De Wit, J.B.F., \& Evers, C. (2011). Planning what not to eat: Ironic effects of implementation intentions negating unhealthy habits. Personality and Social Psychology Bulletin, 37, 69-81. doi: $10.1177 / 0146167210390523$

Adriaanse, M.A., Vinkers, C.D.W., De Ridder, D.T.D., Hox, J.J., \& De Wit, J.B.F. (2011). Do implementation intentions help to eat a healthy diet? A systematic review and meta-analysis of the empirical evidence. Appetite, 56, 183-193. doi: 10.1016/j.appet.2010.10.012

Alinia, S., Hels, O., \& Tetens, I. (2009). The potential association between fruit intake and body weight: A review. Obesity Reviews, 10, 639-647. doi: 10.1111/j.1467789X.2009.00582.x

Baumeister, R.F., \& Heatherton, T.F. (1996). Self-regulation failure: An overview. Psychological Inquiry, 7(1), 1-15. doi: 10.1207/s15327965pli0701_1

Bliese, P.D. (2000). Within group agreement, non-independence, and reliability: Implications for data aggregation and analysis. In K.J. Klein \& S.W.J. Kozlowski (Eds.), Multilevel theory, research, and methods in organizations (pp. 349-381). San Francisco, CA: Jossey-Bass.

Bourget, V., \& White, D.R. (1984). Performance of overweight and normal-weight girls on delay of gratification tasks. International Journal of Eating Disorders, 3(3), 63-71. doi: 10.1002/1098-108X(198421)3:3<63::AID-EAT2260030306>3.0.CO;2-6

Bowers, E.P., Gestsdottir, S., Geldhof, G.J., Nikitin, J., von Eye, A., \& Lerner, R.M. (2011). Developmental trajectories of intentional self regulation in adolescence: The role of parentingand implications for positive and problematic outcomes among diverse youth. Journal of Adolescence, 34, 1193-1206. doi: 10.1016/ j.adolescence.2011.07.006

Byrne, B.M. (2001). Structural equation modeling with AMOS: Basic concepts, applications and programming (2nd edn.). Mahwah, NJ: Erlbaum.

Carver, C.S. (2005). Impulse and constraint: Perspectives from personality psychology, convergence with theory in other areas, and potential for integration. Personality and Social Psychology Review, 9, 312-333. doi: 10.1207/s15327957pspr0904_2

Cole, J., Bellizzi, M.C., Flegal, K.M., \& Dietz, W.H. (2000). Establishing a standard definition for child overweight and obesity worldwide: International survey. $B M J$, 6(320), 1240-1246. doi: http://dx.doi.org/10.1136/bmj.320.7244.1240

Crăciun, C., Tăut, D., \& Băban, A. (2012). Self-regulatory strategies for eating behaviour in children and adolescents: A concept mapping approach. Cognition, Brain, Behaviour, 16(1), 49-66.

Currie, C., Zanotti, C., Morgan, A., Currie, D., de Looze, M., Roberts, C. et al. (Eds.) (2012). Social determinants of health and well-being among young people: Health behavior in school-aged children (HBSC) study: International report from the 2009/ 2010 survey. Copenhagen: WHO Regional Office for Europe. Retrieved from: http://www.euro.who.int/_data/assets/pdf_file/0003/163857/Social-determinantsof-health-and-well-being-among-young-people.pdf

De Vet, E., De Ridder, D., Stok, M., Brunso, K., Baban, A., \& Gaspar, T. (2014). Assessing self-regulation strategies: Development and validation of the tempest 
self regulation questionnaire for eating (TESQ-E) in adolescents. International Journal of Behavioral Nutrition and Physical Activity, 11, 106.

Duckworth, A.L., Tsukayama, E., \& Geier, A.B. (2010). Self-controlled children stay leaner in the transition to adolescence. Appetite, 54(2), 304-308. doi: 10.1016/ j.appet.2009.11.016

Fishbach, A., \& Converse, B.A. (2011). Identifying and battling temptation. In K.D. Vohs \& R.F. Baumeister (Eds.), Handbook of self-regulation: Research, theory, and applications (2nd edn., pp. 244-262). New York: Guilford Press.

Fishbach, A., Friedman, R.S., \& Kruglanski, A.W. (2003). Leading us not unto temptation: Momentary allurements elicit overriding goal activation. Journal of Personality and Social Psychology, 84, 296-309. doi: 10.1037/0022-3514.84.2. 296

Fishbach, A., \& Trope, Y. (2005). The substitutability of external control and selfcontrol. Journal of Experimental Social Psychology, 41(3), 256-270. doi: 10.1016/ j.jesp.2004.07.002

Francis, L.A., \& Susman, E.J. (2009). Self-regulation and weight gain in children from 3 to 12 years. Archives of Pediatrics and Adolescent Medicine, 163, 297-302. doi: 10.1001/archpediatrics.2008.579

Geller, S., Keane, T., \& Scheirer, J. (1981). Delay of gratification, locus of control, and eating patterns in obese and non-obese children. Addictive Behaviors, 6(1), 9-14. doi: 10.1016/S0306-4603(81)80002-0

Gestsdottir, S., \& Lerner, R.M. (2008). Positive development in adolescence: The development and role of intentional self-regulation. Human Development, 51(3), 202-224. doi: 10.1159/000135757

Higgins, E.T. (1997). Beyond pleasure and pain. American Psychologist, 52, 12801300. doi: 10.1093/acprof:oso/9780199765829.001.0001

Hill, A.J. (2002). Developmental issues in attitudes to food and diet. Proceedings of the Nutrition Society, 61, 259-266. doi: 10.1079/PNS2002152

International Association for the Study of Obesity (IASO) (2010). The global epidemic. Retrieved from: http://www.iaso.org/iotf/obesity/obesitytheglobalepidemic/

Johnson, F., Wardle, J., \& Griffith, J. (2002). The Adolescent Food Habits Checklist: Reliability and validity of a measure of healthy eating behavior in adolescents. European Journal of Clinical Nutrition, 56, 644-649. doi: 10.1038/sj.ejcn. 1601371

Junger, M., \& Van Kampen, M. (2010). Cognitive ability and self-control in relation to dietary habits, physical activity and bodyweight in adolescents. International Journal of Behavioral Nutrition and Physical Activity, 7, 22. Retreived from: http:// www.ijbnpa.org/content/pdf/1479-5868-7-22.pdf

Kalavana, T., Maes, S., \& De Gucht, V. (2010). Interpersonal and self-regulation determinants of healthy and unhealthy eating behavior in adolescents. Journal of Health Psychology, 15, 44-52. doi: 10.1177/1359105309345168

Kroese, F.M., Adriaanse, M.A., Evers, C., \& De Ridder, D.T.D. (2011). "Instant success": Turning temptations into cues for goal-directed behavior. Personality and Social Psychology Bulletin, 37, 1389-1397. doi: 10.1177/0146167211410889

Lally, P., Bartle, N., \& Wardle, J. (2011). Social norms and diet in adolescents. Appetite, 57, 623-627. doi: 10.1016/j.appet.2011.07.015 
Levine, T.R., \& Hullett, C.R. (2002). Eta squared, partial eta squared and the misreporting of effect size in communication research. Human Communication Research, 28, 612-625. Retreived from: https://www.msu.edu/ levinet/ eta $\% 20$ squared $\% 20$ hcr.pdf

Luszczynska, A., De Wit, J.B.F., De Vet, E., Januszewicz, A., Liszewska, N., Johnson, F. et al. (2013). How the role of at-home and out-of-home environment on snacks and sweetened beverages intake changes from preadolescence to midadolescence: The interplay between environment and self-regulation. Journal of Youth and Adolescence, 2(12), 1873-1883. doi: 10.1007/s10964-013-9908-6

Metcalfe, J., \& Mischel, W. (1999). A hot/cool system analysis of delay of gratification: Dynamics of willpower. Psychological Review, 106(1), 3-19. doi: 10.1207/ s15327965pli0701_1

Mischel, W. (1996). From good intentions to willpower. In P. Gollwitzer \& J. Bargh (Eds.), The psychology of action (pp. 197-218). New York: Guilford.

Nederkoorn, C., Braet, C., Van Eijs, Y., Tanghe, A., \& Jansen, A. (2006). Why obese children cannot resist food: The role of impulsivity. Eating Behaviors, 7(4), 315322. doi: 10.1016/j.eatbeh.2005.11.005

Reyna, V.F., \& Farley, F. (2006). Risk and rationality in adolescent decision making: Implications for theory, practice, and public policy. Psychological Science in the Public Interest, 7, 1-44. doi: 10.1016/j.dr.2007.08.002

Simmons, R.G., \& Blyth, D.A. (1987). Moving into adolescence: The impact of pubertal change and school context. Hawthorne, $\mathrm{NJ}$ : Aldin.

Steinberg, L. (2008). A social neuroscience perspective on adolescent risk-taking. Developmental Review, 28(1), 78-106. doi: 10.1016/j.dr.2007.08.002

Steinberg, L., Albert, D., Cauffman, E., Banich, M., Graham, S., \& Woolard, J. (2008). Age differences in sensation seeking and impulsivity as indexed by behavior and self-report: Evidence for a dual systems model. Developmental Psychology, 44, 1764-1778. doi: 10.1037/a0012955

Stok, F.M., De Vet, E., De Ridder, D.T., \& De Wit, J.B. (2012). “I should remember I don't want to become fat": Adolescents' views on self-regulatory strategies for healthy eating. Journal of Adolescence, 35(1), 67-75. doi: 10.1016/j.adolescence .2011.06.004

te Velde, S.J.,Twisk, J.W., \& Brug, J. (2007). Tracking of fruit and vegetable consumption from adolescence into adulthood and its longitudinal association with overweight. British Journal of Nutrition, 98(2), 431-438. doi: http://dx.doi.org/ $10.1017 /$ S0007114507721451

Tirosh, A., Shai, I., Afek, A., Dubnov-Raz, G., Ayalon, N., Gordon, B. et al. (2011). Adolescent BMI trajectory and risk of diabetes versus coronary disease. New England Journal of Medicine, 364, 1315-1325. doi: 10.1056/NEJMoa1006 992

Trope, Y., \& Fishbach, A. (2000). Counteractive self-control in overcoming temptation. Journal of Personality and Social Psychology, 79(4), 493-506. doi: 10.1037// 0022-3514.79.4.493

Urdan, T., \& Midgley, C. (2003). Changes in the perceived classroom goal structure and patterns of adaptive learning during early adolescence. Contemporary Educational Psychology, 28, 524-551. doi: 10.1016/S0361-476X(02)00060-7 
Vohs, K.D., \& Baumeister, R.F. (2004). Understanding self-regulation: An introduction. In R.F. Baumeister \& K.D. Vohs (Eds.), Handbook of self-regulation: Research, theory, and applications (pp. 1-9). New York: Guilford.

Whitaker, R.C., Wright, J.A., Pepe, M.S., Seidel, K.D., \& Dietz, W.H. (1997). Predicting obesity in young adulthood from childhood and parental obesity. New England Journal of Medicine, 337, 869-873. doi: 10.1056/NEJM19970925337130 